\title{
Pediatricians urge federal action on pharmacare and gun control
}

— Cite as: CMAJ 2019 July 15;191:E799-800. doi: 10.1503/cmaj.109-5788

Posted on cmajnews.com on June 26, 2019.

W ith the federal election approaching, the Canadian Paediatric Society (CPS) is calling on all parties to support pharmacare and tougher gun controls. However, some members at the society's recent annual meeting questioned why climate change was left off the advocacy agenda.

Pediatricians will be more politically active in the run-up to this year's election, according to Dr. Mike Dickinson, past-president of CPS. The organization is urging Canadians to vote for comprehensive, portable coverage of medicines for children, and a national ban on handguns and assault-style firearms. Both are shaping up to be key election issues.

Canadians pay some of the highest prices in the world for drugs and many cannot afford their prescription medicines, said Dr. Charlotte Moore Hepburn, CPS's director of medical affairs. Coverage of children's medicines can be par-

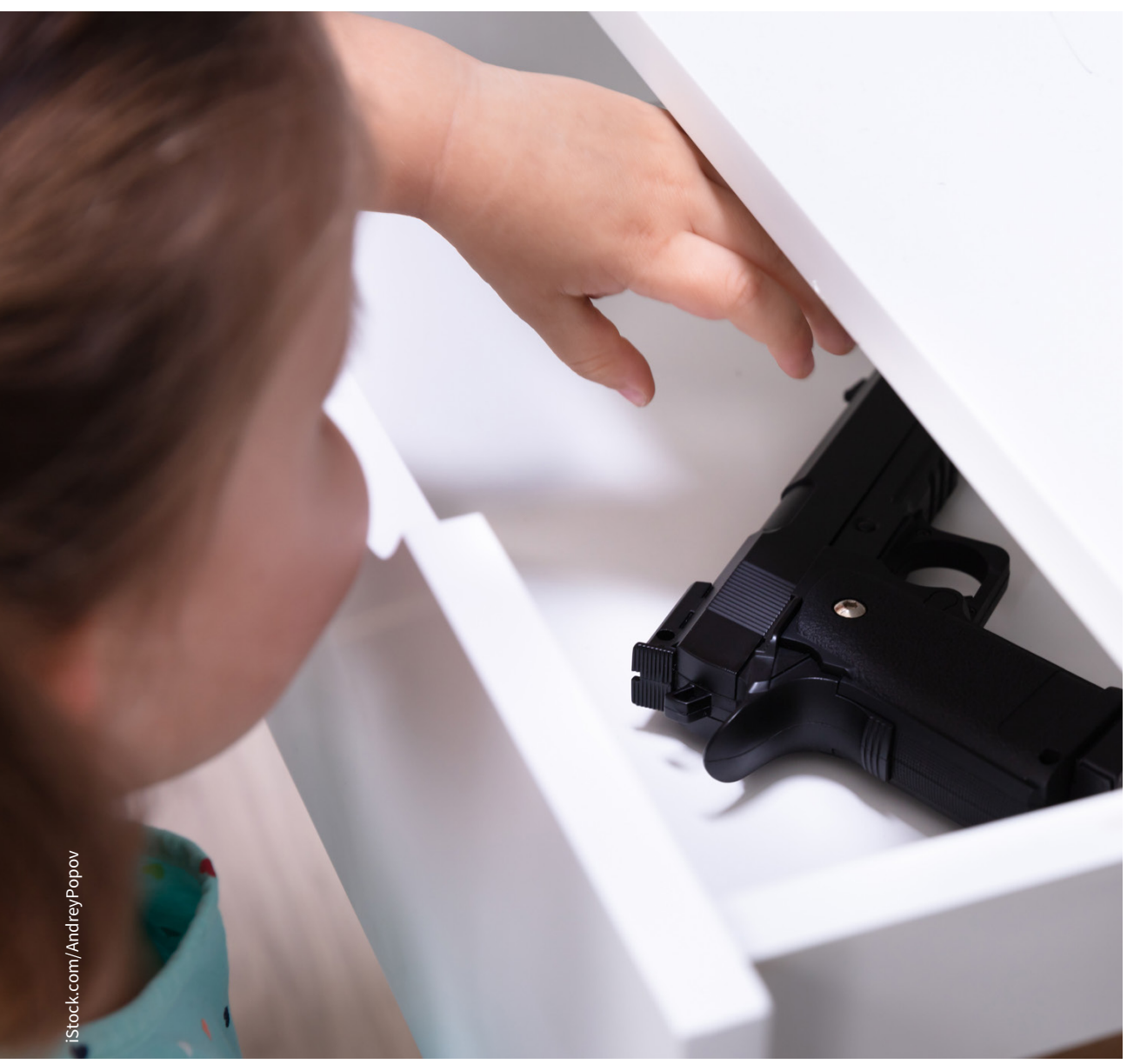

Firearm injuries are a public health emergency, says the Canadian Paediatric Society. ticularly tricky because pediatric prescribing is often off-label.

"We think it's essential to call on the federal government to fund a national, evidence-based, pediatric-sensitive formulary and compounding registry," said Moore Hepburn. The CPS is also advocating for federal regulators to require kid-specific safety data when pediatric use of a drug is expected or anticipated.

A federal advisory panel recently called for the creation of a universal, public pharmacare system to improve access to medicines and lower drug prices. Both the New Democrats and the Liberals have committed to support pharmacare.

Gun control has become another flashpoint for physician advocacy after shootings in the United States and Canada, provoking push-back from gun lobby groups. One group had supporters file regulatory complaints against a Toronto trauma surgeon, alleging her advocacy constituted immoral and unprofessional behaviour.

However, according to Moore Hepburn, "firearm injuries are a public health emergency and our response should be designed as such." Firearms remain a major cause of preventable death and disability in Canada, she said. Many nonpowder guns, such as BB guns, are not regulated because they shoot projectiles at speeds less than 500 feet per second still fast enough to pierce skin and eyes.

The CPS is calling for the regulation of these guns as firearms, as well as a national ban on civilian-owned handguns and assault-style firearms. The organization is also calling for a national suicide prevention action plan, 
as most firearm deaths among youth are suicides.

According to a recent Angus Reid poll, six in 10 Canadians support a handgun ban, and three-quarters support a ban on assault weapons. Last year, New Democrat leader Jagmeet Singh urged the government to give municipalities the power to ban handguns. More recently, Bill Blair, the federal minister of border security and organized crime reduction, said he will propose banning assaultstyle firearms and remains open to cities imposing further restrictions. The Conservative party, meanwhile, is campaigning against a ban on assault weapons, focusing instead on gun smuggling and illegal gun ownership.

Lisa Wolff, director of policy and research at UNICEF Canada, also advised physicians at the meeting to reach out to representatives of all federal parties. "While we might tend to focus on the candidates that we think are more aligned with what we want to accomplish, it's important to try to engage all of them," she said.
Some at the meeting questioned why CPS doesn't have a position on climate change given the short window for action to avert catastrophic health consequences. According to Moore Hepburn, CPS may tackle the issue when the organization refreshes its strategic plan in 18 months. However, Dr. Faruqa Ladha, president of CPS' environmental health section, urged the organization to "step forward before the election."

Lauren Vogel, CMAJ 